\title{
Ileal mesenteric cyst in young patient - Case presentation
}

${ }^{1}$ Emergency County Hospital Piatra Neamt

${ }^{2}$ University "Ovidius" of Constanta, Faculty of Medicine

\begin{abstract}
Mesenteric cysts represent rare diseases of the abdominal cavity. The low incidence and the nonspecific clinical manifestations lead to a difficult diagnosis. Most of the time, these are diagnosed in advanced stages when complications arise or by chance following routine imagistic investigations. The ideal treatment for mesenteric cysts is the total surgical removal. The prognostic is favorable in most of the cases.
\end{abstract}

Keywords: mesenteric cysts, appendicitis, children

\section{Sergiu Chirila}

Faculty of Medicine, Univeristy „Ovidius” of Constanta Universitatii Alee No. 1, Campus B

Constanta, Romania

email : sergiu.chirila@univ-ovidius.ro phone: +40721332068

\section{Case presentation}

A 5 years old, male patient from rural environment presents at the Emergency Department of the Emergency County Hospital Piatra Neamt for:

- Abdominal pain located in the hypogastric and right iliac fossa that started 48 hours before. Initially the intensity was moderate with an increased severity, with colicky characteristics in the last 8 hours. The mother declared that the patients was admitted multiple times to Pediatrics Ward for recurrent abdominal pains.

- Inappetence during the last 24 hours

- Vomiting in the last 8 hours

Clinical examination reveals objective slightly expanded abdominal volume with intense tenderness on palpation of the iliac fossa and hypogastric which outlined muscular defense.

Laboratory exams reveal leukocytosis

Abdominal radiograph shows multiple hydroaeric images in the mesogastric region.

The patients was admitted with a diagnosis of acute appendicitis.

The surgical interventions was done using the Mc Burney incision. During the opening of the 
peritoneal cavity a moderate quantity of serous liquid slightly bloody is observed. The vermiform appendix presented discrete edemas. Ileal loops control reveals a volvulate loop which presents between the adjacent mesentery a cystic, multilocular formation, with thin walls. Through the transparency a liquid content could be observed. Because of this discovery, the incision changes to a median laparotomy.

Devolvulation. The intestinal loop with doubtful viability is removed in block with the cystic formation and we practiced a termino-terminal enteroanastomosis (Figure1).

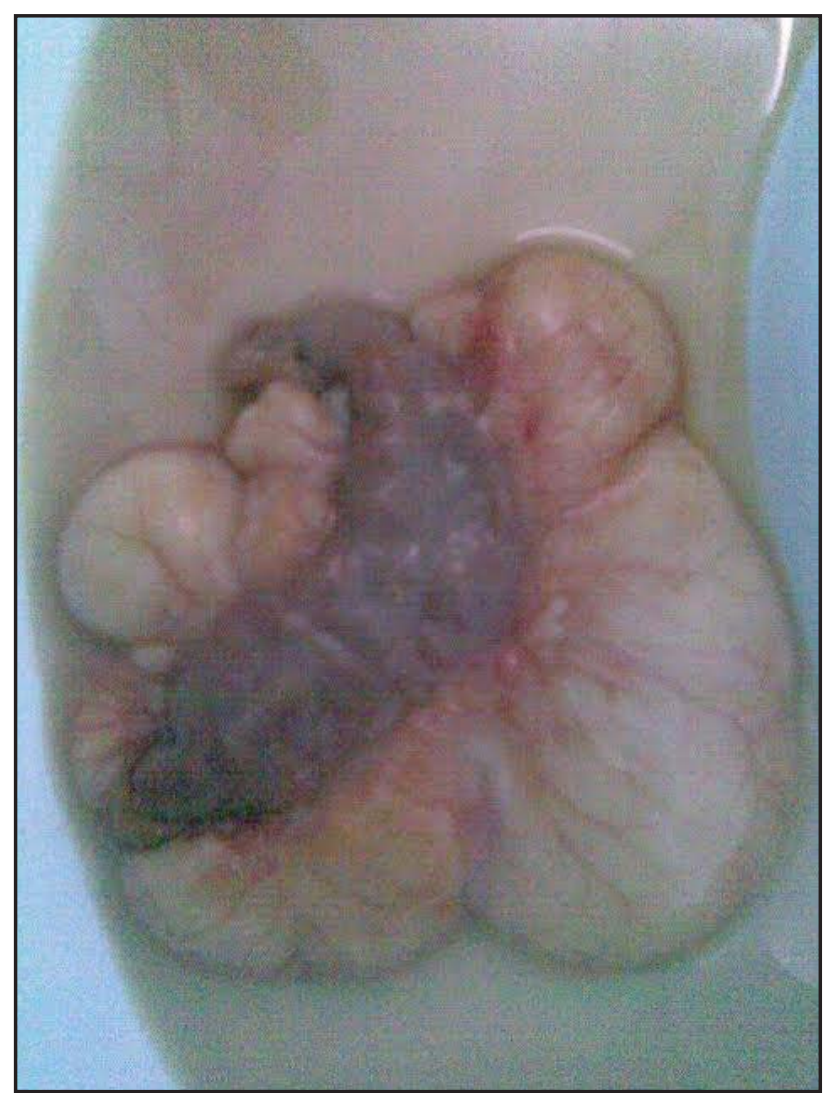

Figure 1 Mesenteric cyst

Post-surgical intervention evolution is favorable with transit restored after 48 hours followed by discharge 7 days post intervention.

Histopathological diagnosis of the extirpated parts is enterogenous, multilocular cyst with thin walls and mucoid content.

\section{Discussions}

The first description of a mesenteric cyst was done by Benevieni following the autopsy of a 18 years old male, in 1507. Rokitansky makes the first description of a lymphatic mesenteric cyst in 1842 . Tillaux resects a mesenteric cyst for the first time in 1880. Pean makes the first marsupialization of a mesenteric cyst. The first laparoscopic excision of a mesenteric cyst has been reported by Mackenzie in $1993[1,2]$.

The precise etiology of mesenteric cysts is unclear. The most accepted theory is proposed by Gross, which states that this is the benign proliferation of ectopic lymphatic vessels which fail to communicate with the lymphatic system, into the mesentery $[3,4]$.

Some studies suggest that, especially in the case of lymphangioma cysts, might develop following trauma, intermittent volvulus, inflammatory processes or surgical interventions $[5,6]$.

The first classification which was accepted was done by Beahrs in 1950. This considers them as being embryonal, traumatic, infectious or neoplastic. The embryonal ones are also classified as enterogenous, with urogenital origin, demoidal or chilo-lymphatic [7].

Currently, following the research of Mennenmayer and Smith, with the help of imunohistological and electronic microscopy studies, the classification currently highly accepted, according to histological criteria, is:

- Cysts of lymphatic origin (simple lymphatic cyst and lymphangioma)

- Cysts of mesothelial origin (simple, beningn and malign)

- Cysts of enteric origin (enteric duplication or enteric)

- Cysts of urogenital origin

- Dermoid cysts (mature cystic teratoma)

- Nonpancreatic pseudocysts (traumatic of infectious origin) $[8,9]$.

Incidence: Most of the studies identify a higher incidence for the males, most of the cases are 
discovered before the age of 10 years and $75 \%$ of the cases below the age of 5 years.

Mesenteric cysts can be localized anywhere in the mesentery of the digestive tract from the duodenum to the rect. $60 \%$ ale localized at jejunoileal level, $24 \%$ at colon level and $14.5 \%$ are localized retroperitoneal $[1,10,11]$.

The cysts have various sizes, are localized between the peritoneal layers, mesenteric roots or can adhere to the intestinal walls.

Clinical manifestations of mesenteric cysts are not specific. There are dependent on the age of the patients, the size and the localization of the cyst, the presence or the absence of the complications.

From statistics conducted on large series of cases, abdominal pain is the most frequent symptom $(82 \%)$ followed by nausea and vomiting $(45 \%)$, constipation $(27 \%)$ and diarrhea $(6 \%)[8,12]$.

Initially the patient is asymptomatic. Abdominal pain and recurrent nausea and vomiting appear as the cyst increases in size.

The complications (intestinal occlusion through volvulus, intracystic hemorrhage, infection and/or rupture) produce a dramatic evolution of the symptomatology: colicky abdominal pain, vomiting, severe alteration of the general condition [10].

The presence of an abdominal tumoral mass that can be observed during palpation and/or using imagistic methods is reported in $62 \%$ of the cases. Most of the times the tumoral formation is smooth, well delimited, elastic and mobile during palpation [8].

Paraclinical examinations with the highest value for diagnosisn mesenteric cysts are:

Ultrasonography - a tumoral formation with liquid content usually can be observed, with thin walls and well delimited.

Computer Tomography - especially done with contrast substances can offer supplementary data about the localization, extension, relations with the intestines and the nature of the cyst.

Differential diagnosis is done with other cystic tumoral formations: pancreatic posttraumatic pseudocyst, renal cysts, suprarenal cysts, ovarian cysts, splenic cysts, hydatid cysts, secondary peritoneal echinococcosis, peritoneal abscess, gastrointestinal duplications etc.
Treatment of mesenteric cysts is strictly a surgical one.

The ideal intervention is cystectomy, but according to local conditions and the status of the patient an internal or internal marsupialization is possible. In some cases the extirpation together with the adjacent intestinal loop is needed [12].

\section{Conclusions}

The clinical manifestations of the mesenteric cysts are not specific, in most of the cases their discovery is incidental while doing routine imagistic examinations or during a surgical intervention in case of complications.

Early diagnosis of the mesenteric cysts is useful in preventing complications.

The ideal treatment is represented by total extirpation of the cysts.

\section{References:}

1. Kurtz, R.J., Heimann, T.M., Holt, J. \& Beck, A.R. (1986). Mesenteric and retroperitoneal cysts. Ann Surg, 203(1), 109-112.

2. Mackenzie, D.J., Shapiro, S.J., Gordon, L.A. \& Ress, R. (1993). Laparoscopic excision of a mesenteric cyst. J Laparoendosc Surg, 3(3), 295 299.

3. Richard, R.R. (2006). Mesenteric and Omental cysts. In J.L. Grosfeld, J.A jr O'neil, A.G. Coran $\&$ E. Fonkalsrud (Eds.), Pediatric surgery (6 ed., pp. 1399-1406). Philadelphia: Mosby Elsevier.

4. Bliss, D.P. Jr, Coffin, C.M., Bower, R.J., Stockmann, P.T. \& Ternberg, JL. (1994). Mesenteric cyst in children. Surgery 115, 571-7. 
5. Weeda, V.B., Booij, K.A. \& Aronson, D.C. (2008). Mesenteric cystic lymphangioma: A congenital and an acquired anomaly? Two cases and a review of the literature. J Pediatr Surg 43, 1206--8.

6. Yoon, H.K. \& Han, B.K. (1998). Chronic midgut volvulus with mesenteric lymphangioma: a case report. Pediatr Radiol, 28(8), 611. doi: 10.1007/ s002470050429

7. Beahrs, O.H., Judd, E.S., Jr. \& Dockerty, M.B. (1950). Chylous cysts of the abdomen. Surg Clin North Am, 30(4), 1081-1096.

8. de Perrot, M., Brundler, M., Totsch, M., Mentha, G. \& Morel, P. (2000). Mesenteric cysts. Toward less confusion? Dig Surg, 17(4), 323-328. doi: 18872

9. Ghidirim, G., Misin, I., Ignatenco, S. \& Sor, E. (2010). Chist al mezocolonului descendent. Chirurgia(105), 855-858.
10. Chung, M.A., Brandt, M.L., St-Vil, D. \& Yazbeck, S. (1991). Mesenteric cysts in children. J Pediatr Surg, 26(11), 1306-1308.

11. Prakash, A., Agrawal, A., Gupta, R.K., Sanghvi, B. \& Parelkar, S. (2010). Early management of mesenteric cyst prevents catastrophes: a single centre analysis of 17 cases. Afr J Paediatr Surg, 7(3), 140-143. doi: 10.4103/0189-6725.70411

12. E Gudumac, E., Babuci, V., Jalbă, A., Petrovici, V., Bernic, J. \& Grăjdieru, M. (2007). Chisturile mezenterice gigante la copil. Buletinul Academiei de Ştiinţe a Moldovei. 3(12), 167-173 